\title{
IMPACTO EN LAS VENTAS DE UNA EMPRESA DEL SECTOR ALIMENTARIO AL IMPLEMENTAR UNA ESTRATEGIA DE MARKETING SENSORIAL OLFATIVO
}

Alejandro Fornelli Martín Del

Campo

Universidad Autónoma de

Ciudad Juárez

Laura Berenice Sánchez

Universidad Popular Autónoma

del Estado de Puebla
RESUMEN

n el tiempo, la evolu-

4 ción del marketing ha

ción para miles de empresas

que se ven beneficiadas por las herramientas que presenta, logrando incrementar el posicionamiento del consumidor, mayor presencia en el mercado, aumento de las ventas y utilidades, entre otros. El avance de la tecnología ha permitido desarrollar nuevas técnicas para lograr un vínculo entre la marca y el consumidor, y una de las más actuales es el marketing sensorial, deri- vado del neuromarketing. Para esta investigación se realizó un experimento sensorial de tipo olfativo utilizando métodos cualitativos y cuantitativos, en el cual se aplicó un olor como herramienta de marketing sensorial olfativo a ciertas unidades de negocio de una empresa del sector alimentario de la zona metropolitana de Puebla. Una vez realizado el experimento, se analizó e interpretó la información obtenida para comparar el impacto en las ventas unitarias de la empresa sujeta al estudio, encontrando que en tres de tres de las uni- 
dades hubo un incremento notable de $9.97 \%$, siendo la sucursal de Xilotzingo - de nivel socioeconómico bajola que mayor variación presentó en unidades vendidas. El aroma implementado que predominó en las tres sucursales fue "frutos rojos" con un total de 5021 unidades vendidas en el periodo del experimento. Adicionalmente, se analizaron tres unidades más que no estuvieron sujetas al experimento y mantuvieron un promedio parcial de $0.27 \%$ en las ventas totales. Existe un incremento en las ventas unitarias entre las mismas sucursales que participaron en el experimento sin aroma en el primer periodo (septiembre, octubre, y noviembre de 2015) y con aroma en el segundo periodo (enero, febrero y marzo de 2016). Debido a la innovación en este tipo de experimentos, se deben considerar las implicaciones éticas de las empresas que utilizan herramientas sensoriales.

Palabras Clave: marketing sensorial olfativo, ética en marketing, impacto en las ventas.
ABstraCT
lution of the market-
ing has represented a solution for thousands of companies who benefit from the tools that offer, increasing positioning in the consumer, higher presence in the market, increased sales and profits, among other benefits. The advance of technology has allowed developing new techniques to achieve a link between the brand and the consumer, and one of the most recent is sensory marketing, derived from neuromarketing. For this investigation, a sensory olfactory type experiment was made using qualitative and quantitative methods of descriptive and correlational type with a transactional and quasi-experimental approach, in which a smell as a sensory marketing tool was applied to certain business units of an enterprise of the food industry in the metropolitan area of Puebla. Once the experiment ended, the information obtained was analyzed and interpreted to compare the impact on unit sales of the company subject to the study, finding that in three out of three units was a con- siderable increase of $9.97 \%$, were Xilotzingo unit, with a low socioeconomic level, had the highest variation in sold units. The smell that prevailed in the three business units was red fruits with a total of 5021 units sold during the experiment period. Additionally, three more units that were not subject to the experiment were analyzed, and maintained a partial average of $0.27 \%$ on total sales. There is an increase in unit sales between the same business units who participated in the experiment without smell in the first period (September, October and November of 2015), and with smell in the second period (January, February and March 2016). Due to the innovation in this type of experiments, ethical implications must be considered by the companies that use sensory tools.

Key words: marketing, consumer behavior, sensory marketing, olfactory system, sales impact. 
Marco Contextual

\section{LA INDUSTRIA}

\section{Alimentaria}

T a industria alimentariase entiende como una 1 parte de la industria que está encargada de todos los procesos relacionados con la cadena alimenticia. Todas sus actividades consisten en el procesamiento y la manufactura de una gran variedad de productos como la carne, el pescado, frutas, vegetales, granos y semillas, entre otros. Todas las compañías que pertenecen a este sector elaboran productos de carácter intermedio como botanas, confitería con cacao y sin cacao, sazonadores, aderezos, productos a base de granos molidos, cereales, galletas, café, té, grasas y aceites, lácteos, productos horneados, entre otros (ProMéxico, 2014). La industria alimentaria se divide en dos categorías: productos frescos y productos procesados, de los cuales, los segundos pasan por algún tipo de procesamiento físico o químico para su conservación y estado (ProMéxico, 2012).

En la actualidad, una gran variedad de insumos industriales tales como los derivados de la agrobiotecnología, se han integrado a la industria debido al gran impacto de nuevas tecnologías e innovaciones que se desarrollan (ProMéxico, 2014).

\section{INDUSTRIA}

\section{ALIMENTARIA}

D 2011, la industria $\checkmark$ global de alimentos 1 procesados tuvo una producción de 520737 millones de toneladas, representando un total de $4462281 \mathrm{mi}$ llones de dólares, y el consumo de la industria de alimentos procesados registró 4443923 millones de dólares (ProMéxico, 2012).

En 2012, la industria global de alimentos procesados alcanzó un valor de producción de 4 657323 millones de dólares, y el consumo 4642717.1 (ProMéxico, 2013).

En 2013, la industria global de alimentos procesados alcanzó un valor de producción total de 4697 miles de millones de dólares, y el consumo de la industria de alimentos procesados tuvo un total de 4667 miles de millones de dólares (ProMéxico, 2014). Como se puede ver en las tablas 1 y 2 , México aumentó su produc-

Tabla 1: Principales Países Productores de la Industria de Alimentos Procesados, 2013

\begin{tabular}{|c|c|c|c|}
\hline País & $\begin{array}{l}\text { Producción } \\
2013(\mathrm{mmd})\end{array}$ & $\begin{array}{l}\text { Crecimiento } \\
2012-2013\end{array}$ & $\begin{array}{c}\text { \% Participación } \\
2013 \\
\end{array}$ \\
\hline China & 1,241 & $12.6 \%$ & $26.4 \%$ \\
\hline Estados Unidos & 719 & $0.8 \%$ & $15.3 \%$ \\
\hline Japón & 243 & $-18.3 \%$ & $5.2 \%$ \\
\hline Brasil & 231 & $0.7 \%$ & $4.9 \%$ \\
\hline Alemania & 171 & $2.5 \%$ & $3.6 \%$ \\
\hline Francia & 156 & $0.3 \%$ & $3.3 \%$ \\
\hline Italia & 143 & $2.3 \%$ & $3.0 \%$ \\
\hline México & 135 & $4.0 \%$ & $2.9 \%$ \\
\hline Rusia & 127 & $7.7 \%$ & $2.7 \%$ \\
\hline España & 105 & $1.0 \%$ & $2.2 \%$ \\
\hline Otros & 1,427 & $-4.4 \%$ & $30.4 \%$ \\
\hline Total & 4,697 & $2.3 \%$ & $100 \%$ \\
\hline
\end{tabular}

Fuente: (ProMéxico, 2014). Elaboración propia. 
ción, crecimiento y porcentaje de participación como país productor y consumidor de la industria global de alimentos procesados.

Para el 2013, el tamaño mundial de la industria de los alimentos procesados se incrementó a 743 millones de toneladas, es decir, un $2.2 \%$ más que en el 2012, y se estima que para el 2018 aumente a 844 millones de toneladas. En la tabla 3 se puede observar el volumen por segmento de la industria mundial de alimentos procesados.
Tabla 3: Volumen por segmento de la industria mundial de alimentos procesados, 2013

\begin{tabular}{lccc}
\hline Categorías & $\begin{array}{c}\text { Volumen } \\
2013,(\text { miles } \\
\text { de toneladas) }\end{array}$ & $\begin{array}{c}\text { \% Participación } \\
\text { Total Industria }\end{array}$ & TMCA \\
& 220,631 & $29.7 \%$ & $2013-2018$ \\
\hline Lácteos & 192,268 & $25.9 \%$ & $1.2 \%$ \\
\hline Panadería & 92,499 & $12.4 \%$ & $3.8 \%$ \\
\hline $\begin{array}{l}\text { Alimentos procesados deshidra- } \\
\text { tados }\end{array}$ & 56,128 & $7.6 \%$ & $5.0 \%$ \\
\hline Aceites y grasas & 39,453 & $5.3 \%$ & $2.3 \%$ \\
\hline $\begin{array}{l}\text { Alimentos procesados conge- } \\
\text { lados }\end{array}$ & 36,080 & $4.9 \%$ & $2.5 \%$ \\
\hline Salsas, aderezos y condimentos & 30,048 & $4.0 \%$ & $2.1 \%$ \\
\hline $\begin{array}{l}\text { Alimentos procesados refrige- } \\
\text { rados }\end{array}$ & 28,259 & $3.8 \%$ & $1.0 \%$ \\
\hline Alimentos procesados enlatados & 14,615 & $2.0 \%$ & $1.9 \%$ \\
\hline Confitería & 14,171 & $1.9 \%$ & $2.8 \%$ \\
\hline Fideos & 18,834 & $2.5 \%$ & - \\
\hline Otros & $\mathbf{7 4 2 , 9 8 5 . 3}$ & $\mathbf{1 0 0} \%$ & $\mathbf{2 . 6 \%}$ \\
\hline Total alimentos procesados & & \\
\hline
\end{tabular}

Fuente: (ProMéxico, 2014). Elaboración propia.

Tabla 2: Principales países consumidores de la industria de alimentos procesados, 2013

\begin{tabular}{cccc}
\hline País & $\begin{array}{c}\text { Producción } \\
\mathbf{2 0 1 3}(\mathbf{m m d})\end{array}$ & $\begin{array}{c}\text { Crecimiento } \\
\mathbf{2 0 1 2}-\mathbf{2 0 1 3}\end{array}$ & $\begin{array}{c}\text { \% Participación } \\
\mathbf{2 0 1 3}\end{array}$ \\
\hline China & 1,247 & $12.6 \%$ & $26.7 \%$ \\
\hline Estados Unidos & 718 & $0.5 \%$ & $15.4 \%$ \\
\hline Japón & 285 & $-16.4 \%$ & $6.1 \%$ \\
\hline Brasil & 192 & $2.7 \%$ & $4.1 \%$ \\
\hline Alemania & 166 & $3.3 \%$ & $3.5 \%$ \\
\hline Francia & 158 & $-0.1 \%$ & $3.4 \%$ \\
\hline Italia & 151 & $1.1 \%$ & $3.2 \%$ \\
\hline Rusia & 142 & $7.8 \%$ & $3.0 \%$ \\
\hline México & 137 & $4.2 \%$ & $2.9 \%$ \\
\hline España & 105 & $-0.4 \%$ & $2.2 \%$ \\
\hline Otros & 1,367 & $-12.4 \%$ & $29.3 \%$ \\
\hline Total & 4,667 & $2.3 \%$ & $\mathbf{1 0 0 \%}$ \\
\hline
\end{tabular}

Fuente: (ProMéxico, 2014). Elaboración propia. 
La participación en la producción mundial por región, fue del 43\% en Asia-Pacífico, $27 \%$ en Europa, 19\% en Norteamérica, $8 \%$ en Latinoamérica y $2 \%$ en otros países, y se estima que la Tasa Media de Crecimiento Anual (TMCA) del 2013-2020 sea del 7.6\% (ProMéxico, 2014).

Como puede observarse, esta industria tiene una importante participación en la producción y consumo de insumos y materias primas. A continuación se presenta el panorama que corresponde a la industria alimentaria en México.

\section{Panorama en México DE LA INDUSTRIA ALIMENTARIA}

n los últimos años, el
crecimiento de la in-
dustria ha sido definido por factores como capacidad productiva, crecimiento económico, recursos agropecuarios y costos bajos de manufactura. En el año 2013, la producción en el país de alimentos procesados fue de 135293 millones de dólares, 4\% mayor al 2012, y representó el 12\% del PIB manufacturero y $4 \%$ del PIB total, mientras que el consumo de alimentos proce- sados fue de 137112 millones de dólares, con un crecimiento anual del 4.2\% (ProMéxico, 2014).

En 2013, la industria alimentaria del país recibió una IED (inversión extranjera directa) de 734 millones de dólares, siendo un total acumulado de 22242 millones de dólares del periodo que comprende del 2003 al 2013. En dicho periodo, los países que mayor IED realizaron en la industria fueron: Países Bajos con un $6.3 \%$, Estados Unidos con $19.6 \%$, Suiza con $18.9 \%$, Japón con $1.4 \%$, y Luxemburgo con $0.9 \%$. Por otra parte, las entidades del país donde se concentró el mayor monto de la IED en la industria fueron: Distrito Federal con $72 \%$ de participación, Nuevo León con 19\%, Guanajuato con $13 \%$, Chiapas con 5\%, y Estado de Mexico 4\% (ProMéxico, 2014). En el mismo año, las ventas en volumen del mercado de alimentos procesados en el país fue de 28424 miles de toneladas, y se espera que el volumen de alimentos procesados crezca a una TMCA del 2.9\% para el periodo 2013 al 2018 (ProMéxico, 2014). Se puede ver en la tabla 4 las cate- gorías con mayor volumen de ventas en el mercado interno, siendo la categoría de panadería la que mayor volumen de mercado tuvo en miles de toneladas y mayor porcentaje de participación en el 2013.

En el año 2012, la industria de elaboración de panadería y tortillas tuvo el $27.2 \%$ del valor total nacional de producción, seguido del $24.5 \%$ de las actividades de matanza, procesamiento de carne y empacado, $10.5 \%$ elaboración de productos lácteos y el 10.2\% molienda de granos y semilla (ProMéxico, 2014). Ver figura 1. 
Tabla 4: Ventas en volumen del mercado de alimentos procesados de México, 2013

\begin{tabular}{llcc}
\hline \multicolumn{1}{c}{ Categorías } & $\begin{array}{c}\text { Volumen } \\
\text { del Mercado } \\
\mathbf{2 0 1 3} \text { (miles } \\
\text { de toneladas) }\end{array}$ & $\begin{array}{c}\text { Partici- } \\
\text { pación } \\
\mathbf{2 0 1 3}\end{array}$ & $\begin{array}{c}\text { TMCA } \\
\mathbf{2 0 1 3}\end{array}$ \\
\hline Panadería & 16,404 & $57.7 \%$ & $1.2 \%$ \\
\hline Lácteos & 7,011 & $24.7 \%$ & $0.5 \%$ \\
\hline Alimentos procesados deshidratados & 1,079 & $3.8 \%$ & $1.7 \%$ \\
\hline Grasas y aceites & 1,004 & $3.5 \%$ & $2.4 \%$ \\
\hline Salsas, aderezos y condimentos & 886 & $3.1 \%$ & $2.7 \%$ \\
\hline Alimentos enlatados & 540 & $1.9 \%$ & $2.3 \%$ \\
\hline Botanas dulces y saladas & 424 & $1.5 \%$ & $1.4 \%$ \\
\hline Confitería & 377 & $1.3 \%$ & $3.4 \%$ \\
\hline Pasta & 320 & $1.1 \%$ & $0.7 \%$ \\
\hline Alimentos procesados refrigerados & 273 & $1.0 \%$ & $3.0 \%$ \\
\hline Alimentos procesados congelados & 143 & $0.5 \%$ & $3.8 \%$ \\
\hline Helados & 78 & $0.3 \%$ & $2.6 \%$ \\
\hline Untables & 77 & $0.3 \%$ & $2.0 \%$ \\
\hline Comida de bebé & 73 & $0.3 \%$ & $3.6 \%$ \\
\hline Fideos & 58 & $0.2 \%$ & $1.4 \%$ \\
\hline Alimentos listos para consumir & 54 & $0.2 \%$ & $1.6 \%$ \\
\hline Barras de botanas & 40 & $0.1 \%$ & $2.6 \%$ \\
\hline Sopas & 28 & $0.1 \%$ & $9.3 \%$ \\
\hline Complementos alimenticios & 13 & $0.0 \%$ & $1.3 \%$ \\
\hline Total alimentos procesados & 28,424 & $100 \%$ & $2.9 \%$ \\
\hline Fuente: (ProMeximen & &
\end{tabular}

Fuente: (ProMéxico, 2014). Elaboración propia.
INDUSTRIA DE LA PANIFICACIÓN EN MÉXICO T a industria panificadora en México, que incluye pasteles, galletas y pan, tiene un valor de 14807 millones de dólares en el mercado, el consumo per cápita es de 53.4 kilogramos al año, y el gasto que se le da a este concepto es de 131.6 dólares (Revista Énfasis Alimentación, 2012). La categoría de productos de panadería, pastelería o galletería se ubicó en el segundo lugar de productos exportados en el 2013, con un valor total de exportaciones de 754 millones de dólares, un crecimiento del 3.1\% del 2012 al 2013, un $8.93 \%$ de participación en el total de exportaciones de la industria, y donde los principales destinos de exportación fueron Estados Unidos con el 91.5\%, Canadá con 1.39\%, Guatemala con 1.10\%, República Dominicana con $0.92 \%$, y Panamá con $0.90 \%$ (ProMéxico, 2014).

En 2013, las exportaciones de alimentos procesados del país se valuaron en 8443 millones de dólares, con una TMCA del 11\% del periodo 2006-2013, siendo Estados Unidos con 69.2\%, Japón con $6.2 \%$, Guatemala con $2.1 \%$, y 
Figura 1: Producción por industria en México, 2012

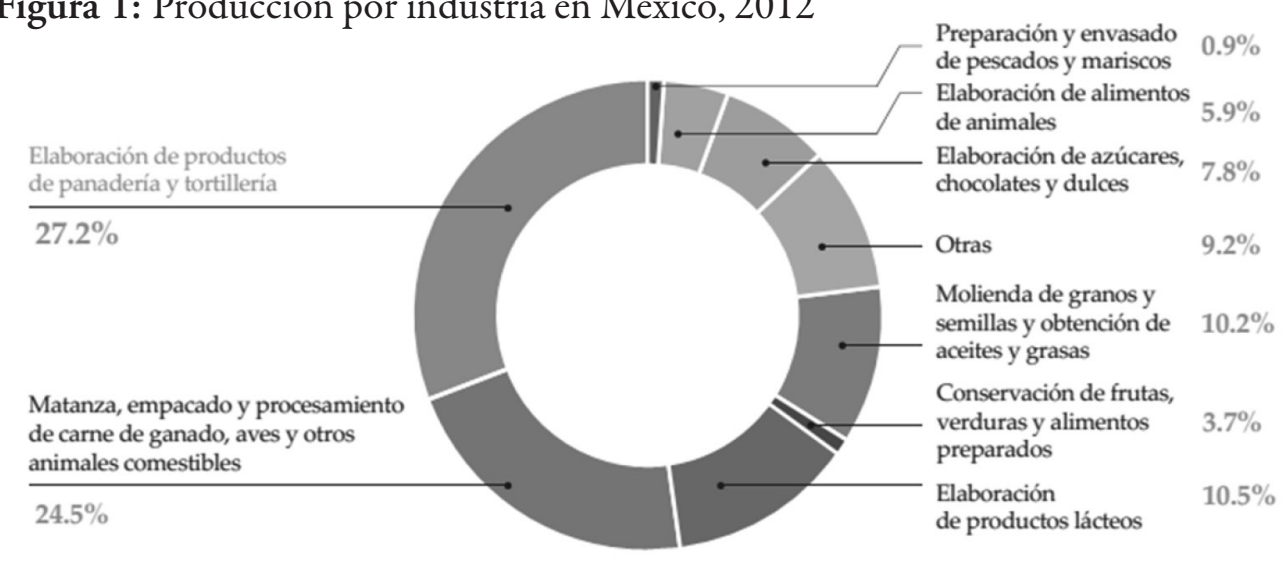

Fuente: (ProMéxico, 2014).

Venezuela con $1.9 \%$ los principales destinos de exportación de alimentos procesados. Las importaciones en México en el 2013 tuvieron un valor de 9710 millones de dólares, lo cual representó un incremento del 2.3\% en relación al 2012, y en el periodo 2006-2013 las importaciones de la industria han crecido a una TMCA del 7\% (ProMéxico, 2014). Los principales proveedores del país en las importaciones totales de la industria fueron Estados Unidos con 69\%, Chile 4\%, China 3,4\%, Canadá 3.4\% y Guatemala 2.5\% (ProMéxico, 2014).

México es el segundo proveedor de alimentos procesados a los Estados Unidos, el tercer productor de alimentos procesados del continente y octavo a nivel mundial; nueve de las diez empresas transnacionales más importantes del mundo están presentes en el país, y 793823 personas están ocupadas dentro de la industria alimentaria (ProMéxico, 2014).

Historia, eVoluCión, Y ESTRATEGIA ACTUAL DE LA EMPRESA PASTELERA SUJETA AL PROYECTO DE INVESTIGACIÓN

T a empresa inició operaciones en enero de 1991, con la colaboración de cada uno de los integrantes de la familia y habilitando un local comercial dentro de la cochera de la casa familiar, abriendo una pastelería y comercializando una línea de pasteles, así como otros productos. Los resultados inmediatos fueron superiores a las expectativas generadas y en el año de 1993, ante los buenos resultados y ante la visión de negocio que se tuvo, se abrió una línea de productos 100\% propia, y se continuó desarrollando ese formato de negocio.

Entre 1993 y 1996 la empresa creció de forma satisfactoria consolidando dos puntos de venta, pero tuvieron problemas de infraestructura, y fue hasta 1997 que se contrataron profesionistas integrantes del mismo núcleo familiar, teniendo como objetivo fortalecer la estructura en ese momento y poder sustentar el crecimiento. 
En 1998, la producción se traslada a un lugar con mejores condiciones para la operación, y se invierte en equipo nuevo, estableciendo mejores procesos logísticos y un crecimiento que permitió que para el año 1999 naciera finalmente la marca de la empresa. Durante los años 2000 y 2001 se incrementó la capacidad de producción, con una ampliación de instalaciones, permitiendo así el aumento de seis a quince puntos de venta en la ciudad de Puebla.

En el año 2002, la empresa invirtió en nuevas instalaciones diseñadas específicamen-

Tabla 5: Refresh de Marca de la "Empresa Pastelera"

\begin{tabular}{ll}
\hline \multicolumn{1}{c}{ Imagen antigua de la empresa } & Refresh de marca de la empresa \\
\hline $\begin{array}{l}\text { El logotipo anterior no cumplía con } \\
\text { los lineamientos de visibilidad y legi- } \\
\text { bilidad básicos, así como arquitectura } \\
\text { visual. }\end{array}$ & $\begin{array}{l}\text { Se ha mantenido la posición de la } \\
\text { marca en el mercado, resultados } \\
\text { positivos en ventas, y expansión } \\
\text { comercial. }\end{array}$ \\
\hline $\begin{array}{l}\text { El ícono (zarzamoras) no eran 100\% } \\
\text { reconocibles. }\end{array}$ & $\begin{array}{l}\text { Conservación de los clientes fieles, } \\
\text { y atracción de nuevos consumi- } \\
\text { dores. }\end{array}$ \\
\hline La tipografía era de fuente común. & $\begin{array}{l}\text { Aceptación de los clientes hacia la } \\
\text { nueva imagen (en cuanto a puntos } \\
\text { de venta). }\end{array}$ \\
\hline $\begin{array}{l}\text { El tag line no aportaba ningún dife- } \\
\text { rencial. }\end{array}$ & $\begin{array}{l}\text { Mejoras considerables en el servi- } \\
\text { cio al cliente. }\end{array}$ \\
Colorimetría adecuada pero no explo- & $\begin{array}{l}\text { Mayor interés por parte de otras } \\
\text { empresas para realizar co-branding, } \\
\text { tada al 100\%. }\end{array}$ \\
\hline
\end{tabular}

Fuente: Elaboración Propia. te para una mejor eficiencia, comprando equipo de alta tecnología para la elaboración de pasteles. Estas nuevas instalaciones permitieron que la empresa tuviera un crecimiento en puntos de venta abarcando ciudades del interior del estado de Puebla y de Tlaxcala, así como dos sucursales más en la Ciudad de México, llegando a un total de 38 puntos de venta a finales de 2004. En 2006 la empresa invirtió en tecnologías de información, adquiriendo el sistema SAP, convirtiéndose en la plataforma de control de los procesos

productivos, logísticos y contables de la empresa.

En el 2008 la empresa se fortalece con tres acontecimientos importantes, los cuales permitieron un crecimiento importante, sumando 44 puntos de venta para el final de ese año: 1) La apertura de una nueva fábrica; 2) La integración del modelo de franquicias; 3) La empresa logró la certificación Endeavor Puebla, lo que abrió una gran oportunidad para un enriquecimiento invaluable a nivel empresarial.

En la tabla 5 se puede observar como estrategia adicional que en el año 2010 la empresa recurre a servicios especializados para el desarrollo de un proyecto de fortalecimiento de marca, resultando el lanzamiento de la nueva imagen de la empresa, acompañado con una nueva filosofía de ventas: "Pasteles para Compartir", y en el año 2011, se inicia con un crecimiento al inaugurar las oficinas corporativas de la empresa.

Para el 2015, la empresa contaba con 160 colaboradoras y 118 colaboradores directos, un centro de producción, un corporativo, dos centros 
de distribución, y 114 puntos de venta distribuidos en cuatro estados de la República Mexicana (Puebla, Tlaxcala, Veracruz y Morelos), más la Ciudad de México.

Con todos estos esfuerzos y la estrategia comercial, la empresa sigue buscando la consolidación como una de las empresas de repostería más importantes del país, compartiendo sus productos cada vez con más clientes, y compartiendo su fórmula de negocios con familias que desean legítimamente mejorar el ingreso familiar y formar un patrimonio.

\section{MARCO TEÓRICO}

Concepto general de la MERCADOTECNIA

1 marketing refiere a
toda la actividad, ins-
tituciones y procesos para crear, comunicar, entregar e intercambiar ofertas que tienen cierto valor para los clientes, socios y la sociedad en general (Lamb, et al., 2011). Es el proceso mediante el cual todas las empresas crean valor para los clientes y solidifican sus relaciones con los mismos, obteniendo el valor del cliente a cambio (Kotler y Armstrong, 2008).
Dentro del marketing, los compradores y los vendedores están conectados por medio de cuatro elementos: 1) La comunicación, 2) Los bienes y servicios, 3) El dinero, 4) La información (Kotler \& Keller, 2012).

El proceso del marketing, consta de cinco pasos: 1) entender el mercado, deseos y necesidades de los clientes, 2) diseñar estrategias de marketing impulsadas por el cliente, 3 ) elaborar programas que entreguen un valor superior, 4) crear relaciones redituables para los clientes, y 5) captar el valor de los clientes para crear utilidades y calidad para el cliente, buscando crear valor para los clientes y construir relaciones, y a cambio, atraer el valor del cliente a la empresa (Kotler \& Armstrong, 2008). El marketing, durante toda su historia, ha mostrado mucha evolución, innovaciones y estrategias que con el paso del tiempo han ofrecido soluciones integrales para todo tipo de empresas, y así sobresalir en los mercados competitivos actuales.

En marketing, una de las principales causas por las cuales muchas empresas fracasan, es la falta de conocimiento de todas aquellas necesidades que los consumidores tienen, y la forma de satisfacerlas. Todos los consumidores y el entorno social en el que se desenvuelven es cambiante y evolutivo, por lo cual se deben ajustar constantemente las estrategias de marketing y poder ofrecer soluciones a cada uno de los segmentos (Maldonado, 2008).

El marketing moderno como parte de la diferenciación y el posicionamiento, ha empezado a utilizar herramientas que jamás se hubieran pensado en el pasado, y que ayudan a ganar terreno a las marcas en el cerebro del consumidor. Una de estas herramientas es el marketing sensorial (Dani \& Pabalkar, 2013). Una de las estrategias dentro del marketing sensorial, es implantar la marca en el consumidor como una identidad olfativa (Gómez, 2012). Muchas empresas implementan las herramientas del marketing sensorial debido al proceso interno del consumidor y al comportamiento que adopta al estar vinculados los cinco sentidos: el gusto, el tacto, el 
olfato, el oído y la vista (Dani \& Pabalkar, 2013).

\section{EvOLUCIÓN DE LA} MERCADOTECNIA

antesmases, citado en
Martínez (2011), señala
que el marketing constituye una forma distinta y particular de ejecutar las funciones comerciales de una empresa, y las relaciones de intercambio entre las partes involucradas. La evolución del marketing está dividida en varias fases, las cuales están distinguidas por diferentes acontecimientos durante el paso del tiempo, y se asocian a las formas de hacer marketing, y en que se concibe el cliente (Martínez, 2011).
Las fases evolutivas del marketing son las siguientes:

a) Fase de distribución y producción (de 1850 a 1920)

Todo lo que se producía se vendía, no existía competencia y el consumidor no tenía el conocimiento para elegir entre los diferentes ofertantes.

b) Fase de ventas (de $1920 \mathrm{a}$ 1950)

Esta fase se caracteriza principalmente por el hecho de que se vendía todo lo que se producía, y los productores se acercaban al consumidor de forma persuasiva, convencidos de que eran superficiales y poder presionar la venta. c) Fase de marketing propiamente dicha (de 1950 a la actualidad)

En esta fase se comenzó a desarrollar un enfoque real del marketing, en donde las empresas realizaban esfuerzos por adaptarse a los consumidores, y empezaron a identificar los deseos y necesidades del mercado.

A continuación se muestra la evolución conceptual del marketing dividida en cuatro grupos (figura 2), y que busca establecer una situación temporal como marco referencial.

Figura 2: Evolución Conceptual del Marketing

\begin{tabular}{|c|c|c|c|c|}
\hline & Bartels (1988) & Munuera (1992) & Kerin $(1996)^{*}$ & Bigné (1996) \\
\hline Hasta 1900 & Antecedentes & \multirow{3}{*}{$\begin{array}{c}\text { Periodo de } \\
\text { identificación }\end{array}$} & \multirow{4}{*}{ No considerado } & Orígenes \\
\hline $1900-10$ & Descubrimiento & & & \multirow{6}{*}{ Preconceptual } \\
\hline $1910-20$ & Conceptualización & & & \\
\hline $1920-30$ & Integración & \multirow{2}{*}{$\begin{array}{l}\text { Periodo funcionalista } \\
\text { (1945) }\end{array}$} & & \\
\hline $1930-40$ & Desarrollo & & Economía aplicada & \\
\hline $1940-50$ & Nueva estimación & \multirow{2}{*}{ Periodo preconceptual } & Actividad directiva & \\
\hline $1950-60$ & Reconcepción & & Ciencia cuantitativa & \\
\hline $1960-70$ & Diferenciación & \multirow{4}{*}{$\begin{array}{l}\text { Periodo de definiciones } \\
\text { formales }\end{array}$} & $\begin{array}{c}\text { Ciencia } \\
\text { comportamental }\end{array}$ & $\begin{array}{c}\text { Conceptualización y } \\
\text { ampliación del campo } \\
\text { de actuación }\end{array}$ \\
\hline $1970-80$ & Socialización & & $\begin{array}{c}\text { Ciencia de la toma de } \\
\text { decisiones }\end{array}$ & \\
\hline $1980-90$ & \multirow{2}{*}{ Concepto actual } & & \multirow{2}{*}{ Ciencia integrada } & AMA (1985) \\
\hline $1990-$ & & & & Integración \\
\hline
\end{tabular}

Fuente: (Bigne, citado en Moliner \& Cervera, 2005). 
ESCUELAS DE MERCADOTECNIA

T os autores Sheth, et al., (1988), propusieron un $\mathcal{L}$ enfoque para clasificar todos los pensamientos y escuelas existentes del marketing (tabla 6), en donde se agruparon en cuatro dimensiones: interactivas, no interactivas, económicas y no económicas.

Las escuelas interactivas se centran en las relaciones interdependientes que tienen todos los agentes del marketing, y las no interactivas se enfocan en todas las actividades que un agente de marketing realiza e influencia al resto de los agentes.

\section{COMPORTAMIENTO DEL} CONSUMIDOR

T 1 comportamiento del $\checkmark$ consumidor se define como aquel comportamiento que se tiene al buscar, comprar, utilizar, evaluar y deshacerse de productos y servicios que esperan les satisfagan ciertas necesidades. El comportamiento del consumidor está basado en la forma en que los consumidores que integran hogares, y familias, toman decisiones para invertir los recursos que tienen disponibles incluyendo tiempo, dinero y esfuerzo (Schiffman \& Lazar, 2010).

Todo consumidor pasa por un proceso de decisión de compra, y es importante mencionar que el proceso comienza tiempo antes de realizar la compra, y presenta consecuencias después de la compra. El proceso de decisión de compra es el siguiente:

- Reconocimiento de la necesidad: se reconoce la necesidad, se plantea el problema y se compara el estado actual sin la necesidad satisfecha, con el deseado.
- Búsqueda de Información: se busca información por medio de publicidad (radio, tv, folletos, etcétera) con conocidos, profesionales, familia, acudiendo a puntos de venta, etcétera.

- Evaluación de alternativas: se comparan los beneficios de las marcas investigadas y se valoran las características de mayor interés.

- Decisión de Compra: se decide la marca y cantidad a comprar.

- Comportamiento postcompra: este comportamiento se presenta una vez que el consumidor evaluó el nivel de satisfacción obtenido al consumir su producto, resultando en factores positivos o negativos hacia la marca, e influyendo en la recompra o abandono de marca.

Tabla 6: Escuelas del Pensamiento del Marketing.

\begin{tabular}{lll}
\hline Dimensiones & No interactivas & Interactivas \\
\hline \multirow{2}{*}{ Económicas } & Escuela de Commodity & Escuela Funcional \\
& Escuela Funcional & Escuela Activista \\
& Escuela Geográfica & Escuela del Management \\
\hline \multirow{3}{*}{ No Económicas } & Escuela del Comportamiento del Consumidor & Escuela de la dinámica organizativa \\
& Escuela Activista & Escuela de sistemas \\
& Escuela de macro-marketing & Escuela de intercambio social \\
\hline
\end{tabular}

Fuente: (Sheth, et al., 1988). Elaboración Propia. 
Por otro lado, debe entenderse que el consumidor tiene una gran cantidad de procesos internos que lo llevan a tomar ciertas decisiones para la adquisición de sus bienes y servicios, pero ¿Qué es el comportamiento del consumidor? El comportamiento del consumidor se define como aquel comportamiento que se tiene al buscar, comprar, utilizar, evaluar y deshacerse de productos y servicios que esperan les satisfagan ciertas necesidades (Schiffman \& Lazar, 2010). El comportamiento del consumidor está basado en la forma en que los consumidores que integran hogares, $\mathrm{y} f a-$ milias, toman decisiones para invertir los recursos que tienen disponibles incluyendo tiempo, dinero y esfuerzo (Schiffman \& Lazar, 2010).

Existen varias posturas sobre las cuales el estudio del comportamiento del consumidor se ha hecho importante hoy en día, y es debido a que el consumir y comprar bienes, se ha convertido en una forma de ser, combinado con varios elementos como lo son el nivel cultural, la clase social, los diferentes estilos de vida, características psicológicas, edad, sexo, gustos y preferencias, nivel de ingresos, etcétera (Maldonado, 2008). Mucha de la investigación realizada orientada hacia el análisis de los efectos de la identificación entre el consumidor y la empresa (C-E), ha centrado su objetivo en analizar las respuestas del consumidor en relación al comportamiento, el afecto y el cognitivismo (Curras, 2012).

\section{ESCUELA DEL COMPORTAMIENTO DEL CONSUMIDOR \\ $\square$ sta escuela pertenece 4 al grupo de no econó- micas y no interactivas,} la cual se enfoca en el interés comportamental, social y psicológico dentro del marketing. Estas escuelas del pensamiento mercadológico dan lugar a un cambio significativo en la historia del pensamiento mercadológico (Sheth, et al., citados en Moliner \& Cervera, 2005). Todos los investigadores de la escuela del comportamiento del consumidor no aceptan que el consumidor no solamente se comporta de manera irracional, y argumentan que todos los estudiosos del marketing deben de investigar las causas verdaderas de su comportamiento. Finalmente, esta escuela se caracteriza por el predominio de estudios cualitativos, interculturales y de subculturas (Moliner \& Cervera, 2005).

\section{VARIABLES ENDÓgENAS Y EXÓGENAS EN EL COMPORTAMIENTO DEL CONSUMIDOR}

T os factores básicos que influyen en el estilo de vida son doce: actividades de marketing, cultura, valores, aspectos demográficos, estatus social, grupos de referencia, hogar, personalidad, emociones, motivos, percepción y aprendizaje (memoria), y se clasifican en dos grandes grupos: influencias externas e influencias internas. Las influencias primeras son la cultura, los valores, aspectos demográficos, el status social, los grupos de referencia y el hogar, mientras que las influencias internas son la percepción, el aprendizaje y memoria, motivos, la personalidad y las emociones, estilos de vida y las actitudes (Hawkins, et al., 2004). Para Schiffman \& Kanuk (2005), en los consumidores como individuos existen dinámicas internas que son la percepción, el aprendizaje y memoria, motivación y valores, 
el yo, la personalidad y estilos de vida, las actitudes el cambio de actitudes y comunicaciones interactivas y las dinámicas externas, que son la toma de decisiones individual, la compra y el desecho, la influencia de los grupos y liderazgo de opinión, la toma de decisiones en las organizaciones y el hogar.

\section{Sistema OlFATIVO}

71 olfato es el más pri4 mitivo de los cinco sentidos, y el más complicado de explicar para la ciencia. La función principal del olfato es distinguir las funciones extrañas y no extrañas e informar al organismo sobre los cambios en el medio ambiente. Los sensores olfatorios se ubican en la entrada del sistema respiratorio y controlan la calidad de lo que se respira. Toda sustancia nociva provoca una alarma, bloqueo o expulsión de la misma mediante el estornudo (Guiraro, p. 283, citado en Bonadeo, 2005). El sentido del olfato es una de las ventanas más importantes por medio de las cuales los humanos captan la información del mundo exterior, y por lo cual son capaces de modificar su comportamiento hacia deter- minados ambientes y alimentos (Guzmán, et al., 2010).

\section{FUNCIONAMIENTO DEL SISTEMA OLFATIVO}

71 sentido del olfato es $\checkmark$ diez mil veces más sensible que cualquiera de los sentidos, y es único de los sentidos en el cual el sistema nervioso central está expuesto de forma directa al medio ambiente. Sentidos como el tacto y el gusto viajan por el cuerpo a través de las neuronas y la médula espinal antes de llegar al cerebro, mientras que el olfato es de respuesta inmediata y se va directamente al cerebro. $\mathrm{El}$ proceso del olfato se compone de los siguientes pasos (Maldonado, et al., 2012).

\section{1) Las moléculas del olor (compuestos químicos) que están flotando en el aire llegan a las fosas nasa- les y se disuelven en las mu- cosidades.}

2) Debajo de las mucosidades, se encuentran las células receptoras denominadas neuronas receptoras del olfato, las cuales detectan los olores.

3) Las neuronas receptoras del olfato transmiten la información a los bulbos ol- fatorios que se encuentran en la parte de atrás de la nariz.

4) Los bulbos olfatorios tienen receptores sensoriales que forman parte del cerebro y son los que envían mensajes a la parte medular del cerebro estimulando las emociones y memorias, modificando los pensamientos conscientes.

5) Los centros cerebrales perciben el olor y acceden a recuerdos relacionados con personas, lugares, o situaciones que se relacionan con las sensaciones olfativas.

6) Finalmente el epitelio olfativo, tiene unas glándulas que segregan una solución enzimática que elimina las moléculas olorosas que han despertado las neuronas correspondientes, y limpiando la mucosa olfativa de las sustancias presentes que ya fueron detectadas.

Cuando una persona percibe directamente un aroma, la primera respuesta es una sensación que inmediatamente se convierte en una emoción, y de dicha emoción, se comienza un proceso de asociaciones mentales del aroma hacia 
una marca, obteniendo como resultado una actitud o conducta. La conducta deja una huella presente en el cerebro de la persona, y está presente durante toda su vida, lo cual condiciona sus procesos pensativos y acciones futuras (Gómez, 2012).

LA MERCADOTECNIA EN EL SISTEMA OLFATIVO

a principal función de la
sensibilidad, es identifi-
car aquellos elementos que se le presentan a un organismo en el ambiente. El desarrollo sensorial que los humanos han alcanzado les permite tener un proceso de información del ambiente e identificar estímulos. En cuestión de identidad aplicada en la mercadotecnia, se afirma que los humanos cuentan con una sensibilidad que les permite distinguir varias cualidades sensibles entre productos y servicios. Las personas cuentan con las capacidades suficientes para identificar una marca a través del oído y la vista, pero también con el olfato entre otros sentidos (Bonadeo, 2005).

Los olores son moléculas que están sueltas en el aire, y son percibidas por el cerebro al ingresar por los orificios de la nariz (Gibbons, citado en Bonadeo, 2005). El olfato funciona no olvidando que recordando, y las memorias olfativas por lo general son altamente emocionales, vívidas, extrañas y relativamente viejas (Rubin, Groth \& Goldsmith, citados en Bonadeo, 2005). Existen varias razones sobre el poder del olfato y del significado social que representan. Entre las más importantes destacan las siguientes (Synnott citado en Bonadeo, 2005): altamente personal, psicológicamente directo, disparador de recuerdos, disparador de emociones y modifica la conducta.

Así como existen logotipos e isotipos, también existen "odotipos", que se asocian con una forma aromática estable y que se cuentan como uno más de los elementos para la identificación de una marca. Autores como Wilkie \& Curtis, ven el olfato un poderoso motivador para las ventas debido a la conexión entre el olor, la memoria y el estado de ánimo, y creen que los aromas son muy importantes para los consumidores, ya que estos combinan la biología con la psicología (Bonadeo, 2005).
Las hipótesis del marketing sensorial indican que las compañías deberían aplicar estrategias sensoriales y sensaciones directamente a la mente del consumidor (Hulten, 2011). Entre más experiencia tenga un consumidor de un producto, mayor será la recordación de los beneficios que obtiene y de la marca (Dani \& Pabalkar, 2013). Hablando de las sensaciones sensoriales, los sentidos son la base sobre la cual se interpreta el mundo, y es por eso que definitivamente es como se afecta el comportamiento de los seres humanos (Gómez, 2012). De los cinco sentidos, el olfato ha permanecido por años como el más enigmático, ya que el ser humano tiene la capacidad para reconocer y recordar aproximadamente 10 000 olores diferentes (Álvarez, 2011).

Como puede apreciarse, existe una tendencia hacia incluir herramientas de marketing sensorial como estrategias para modificar el comportamiento de compra del consumidor e incrementar las ventas en una empresa. En la actualidad, los consumidores cada vez son más exigentes, y el mercado es más competiti- 
vo, lo cual hace difícil para las empresas diferenciar su marca y posicionarse entre los consumidores (Gómez, 2012).

IMPLICACIONES ÉTICAS EN Marketing Sensorial CONCEPTO GENERAL DE ÉTICA

ntes de poder a de-
finir los conceptos
fundamentales de la ética, se debe comprender la derivación filosófica de la ética y el papel que ejerce al tomar decisiones de diferente índole. La ética se originó en la época antigua cuando se convirtió en una preocupación el determinar qué estaba bien y qué estaba mal, y el pensamiento humano evolucionó a través del tiempo hasta percibir la ética como una ciencia moral que contiene normas morales que nacen en la misma persona y no se imponen externamente (Jiménez et al., 2010).

La palabra ética proviene del griego antiguo que se deriva de los vocablos Ethos/ ëthos, que significa residencia, lugar donde habita, carácter, personalidad, y Êthos, que significa costumbre y hábito. Hay muchas definiciones de ética que han surgido durante el paso de los años, pero algu- nas importantes son la de los autores Vázquez, citado en Jiménez (2010), quien define a la ética como "la ciencia de la conciencia universal bajo la moralidad del obrar humano, basada en un conocimiento científico y organizado de la finalidad de la vida humana y de los medios para alcanzar los fines ideales; posee cinco funciones: 1) moralizadora, 2) personalizadora, 3) de denuncia, 4) utópica, y 5) creadora de valores". El autor Barroso, citado en Jiménez (2010), define a la ética como "la ciencia filosófico-normativa y teóricopráctica que estudia aspectos individuales y sociales de la persona, sujeta a la moralidad de los actos humanos, bajo el prisma de la razón humana, y teniendo siempre como fin el bien honesto". Por último, el autor Márquez, citado en Jiménez, (2010), define la ética como "la parte de la filosofía que trata de la moralidad de las acciones humanas para encaminarlas al fin último."

La ética tiene como objetivo estudiar todas aquellas conductas que se rigen por normas morales, como lo son la mentira, el robo, los sobornos, etcétera, se ocupa de lo bueno y lo malo, lo justo e injusto, y se deriva de términos que significan costumbre o conducta. Para poder entender de forma clara el objeto de la ética, se debe tener en cuenta que siempre serán las actividades de persona a persona, es decir, todos los actos que se califican como buenos o malos, y dicho objeto se divide en formal y material. El objeto material son todos los actos libres en donde la persona tiene pleno conocimiento de lo que hace, y la libertad para realizar sus acciones. El objeto formal son todos aquellos actos que pueden calificarse como buenos o malos desde el punto de vista de la moralidad (Jiménez et al., 2010).

\section{Doctrinas Éticas \\ T as doctrinas éticas na- cieron y se desarrolla- ron en las diferentes so- ciedades debido a los proble- mas que se presentaban entre las relaciones humanas, resul- tando así, una vinculación en- tre el comportamiento moral, y la realidad de las personas, la cual fue cambiando histórica- mente. La ética, la historia y la vida social tienen una fuerte relación, pero específicamente}


la vida social, está muy vinculada a las cuestiones morales y conectadas a cada una de las doctrinas que surgieron antes y después (Alfaro, 2012).

Cuando los principios, valores o normas entran en un estado de crisis, hay que aclararlos o cambiarlos, y es ahí, cuando la ética tiene la necesidad de realizar nuevas teorías morales para poder responder a la incertidumbre y confusión que le provoca a las personas cuando los conceptos de valores y normas se convierten en un problema (Alfaro, 2012).

Durante las etapas de las doctrinas éticas, todas las actividades comerciales y empre-

Figura 3: Doctrinas Éticas

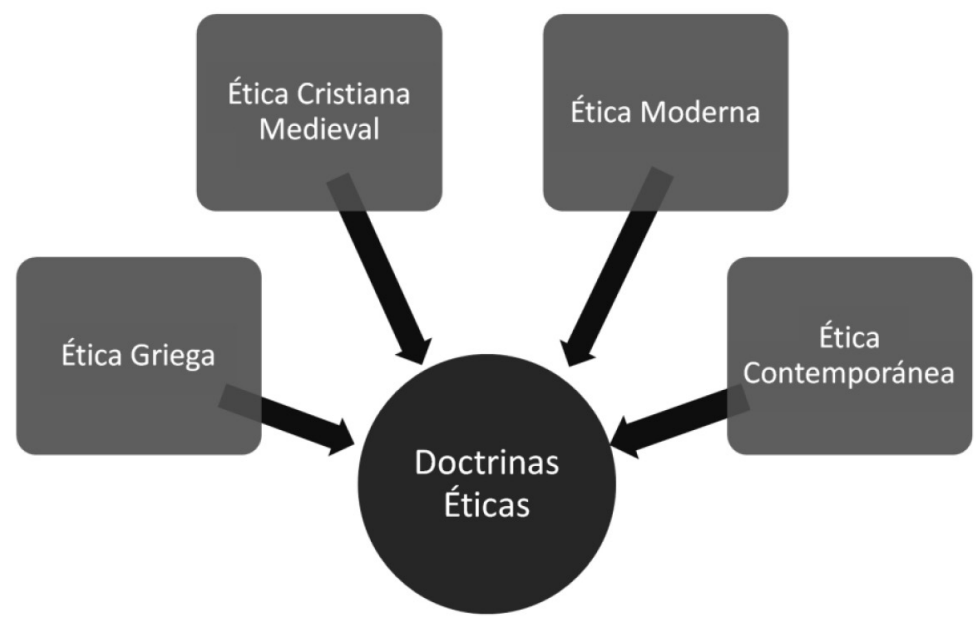

Fuente: (Alfaro, 2012). Elaboración propia sariales han sido afectadas por no ser siempre empresas respetables, y durante gran parte de la historia, la percepción ética de los negocios ha sido en su mayoría negativa (Jiménez et al., 2010). La figura 3 muestra un mapa conceptual de la evolución de las doctrinas éticas durante el tiempo.

\section{ÉTICA EN EL MARKETING}

omo primera instancia, se debe mencionar que la ética empresarial es también conocida como ética en la gestión de la empresa, y ética en los negocios, y es debido a que los au-

tores de la ética empresarial se refieren de manera semejante a un objeto de análisis (Cuevas, 2005). La empresa es parte de un cuerpo social, y por tal motivo, la ética empresarial juega un papel importante en las relaciones internas y externas de la empresa. La ética empresarial se justifica por la necesidad de la orientación ética para la gestión de la empresa de tres maneras. La primera de ellas se da cuando los empresarios y administradores deben tomar decisiones que implican cierto nivel de responsabilidad, y por tal motivo, la moral. La segunda, cuando los cambios que existen en el mundo actual requieren la intervención de las empresas para asuntos sociales, simbolizando a la empresa como "empresa ciudadana", y sus implicaciones morales. La tercera se presenta cuando las empresas en la actualidad ofrecen espacios de autonomía para los empleados, y donde la comunicación toma un papel muy importante para la administración (empresas inteligentes) (Cuevas, 2005).

Existen varios modelos teóricos sobre el comportamiento ético y no ético en las empresas que ayudan a predecir el com- 
portamiento de las personas dentro de la misma cuando se presentan dilemas morales, y la mayoría de los modelos describen qué factores son los que influyen en las decisiones y comportamientos éticos y no éticos de los empleados. Como se muestra en la figura 4, los autores Hunt \& Vitell, citados en Ruiz (2011), desarrollaron un modelo que describe la ética de una situación o problema que se involucra con el proceso de toma de decisiones, partiendo desde el punto de que todo comienza con la percepción del empleado en relación al problema que implica las cuestiones éticas para resolverse.

Cuando un problema es percibido, hay varios factores que se involucran y se clasifican como factores de entorno como la cultura, la industria, la organización, etcétera, y los factores personales o experi- mentales como la religión, los valores, las creencias, la fuerza del carácter moral, cognitivismo moral y la sensibilidad ética. Una vez que se percibe el problema moral se determinan las opciones para resolverlo y conducen al individuo a realizar sus juicios éticos partiendo de los criterios deontológicos (estudio o creencia de los hechos bajo normas morales) y/o teleológico (estudio de los

Figura 4. Modelo de Toma de decisiones y comportamiento ético y no ético

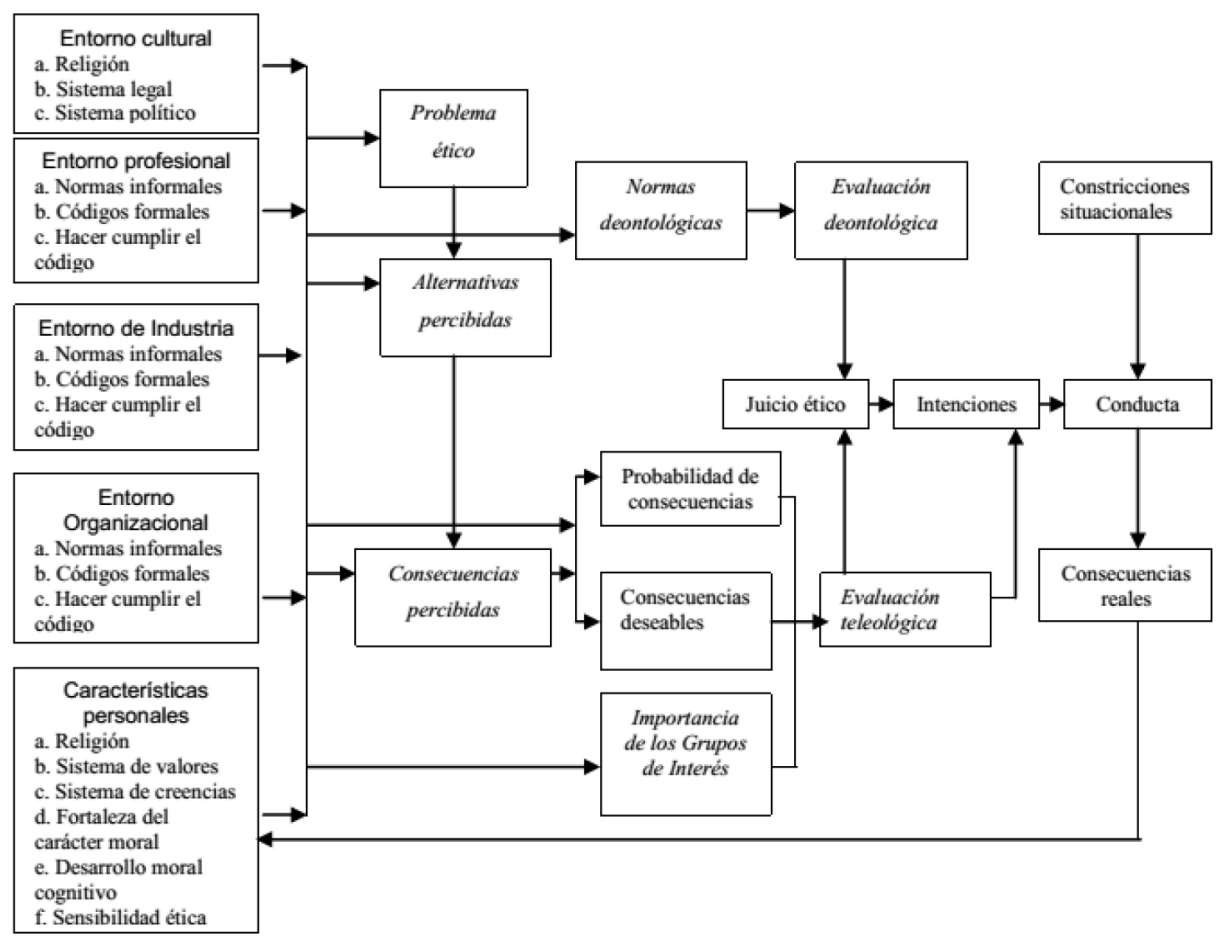

Fuente: (Hunt \& Vitell, citados en Ruiz, 2011). 
fines o propósitos de algún objeto) (Ruiz, 2011).

En nuestro país, la ética es totalmente diferente a las regulaciones impuestas por la ley, ya que las leyes gubernamentales nacen de un conjunto de principios y reglas que dicen cómo debe actuar el individuo, y son aceptadas y cumplidas por la sociedad. Por otra parte, las normas éticas en su mayoría, son aplicadas por conductas que la ley no contempla, y hoy en día existe una gran cantidad de conductas que no se han registrado en el sistema jurídico nacional, las cuales, las empresas deben de hacerse responsables a las normas y valores que surgen en el entorno interno y externo (Ugarte, 2007).

Hablando específicamente del marketing, la autora Sainz de Vicuña, citada por Torres (2007), argumenta que la planeación estratégica es igual a la planeación del marketing, y esto, debido a la importancia que tiene la mercadotecnia sobre las estrategias generales de las organizaciones. Las personas que se encargan de tomar las decisiones de marketing, en ocasiones generan conflicto con otras áreas de la empresa, y es por eso que todas las acciones responsables de esta área se toman como ejemplo para el resto de la empresa.

Gronröos, citado en Torres, (2007), argumenta que el marketing no solo es de los especialistas, sino que cada miembro de la empresa debe de adoptarlo para entender al cliente y generar valor, pero en esa área, es donde las empresas generan más abusos éticos. Robin \& Reidenbach, citados por Torres (2007), afirman que el hecho de que en el marketing se den relaciones desiguales, aunado con la posibilidad de ejercer a beneficio o en contra del público en general, es un motivo para defender la existencia de la ética en el marketing.

Algunos de los problemas éticos que se presentan en el marketing y sus responsables, son regalos, publicidad engañosa y/o falsa, presentación distorsionada de bienes tangibles e intangibles, la capacidad real de las compañías, mentiras a clientes para concretar ventas, manipulación de datos, invasión de la vida privada del cliente, precios engañosos, competencia desleal, entre muchos otros, y Brenkert, ci- tado en Torres (2007), opina que se debe hacer investigación sobre si el marketing ha cumplido con las fuerzas morales externas de la sociedad.

Muchas empresas han establecido códigos de ética para ayudar a los encargados del marketing a tomar mejores decisiones, y seguir una lista de pasos es un ejemplo útil, aunque no siempre se cumpla al tomar decisiones. Tarrago, citado del Torres (2007), propone varios elementos éticos como la veracidad, la fidelidad a las promesas (lealtad), y la confidencialidad. La confidencialidad se refiere a guardar secretos en ciertas cuestiones profesionales, y la calidad de "reservados" que tiene cierta información la cual su difusión está restringida. La veracidad se da por su fundamentación ética, y está en el principio de respeto por la autonomía de las personas, y esta regla sería de índole inmoral en el caso de que se quiera engañar a la persona para hacerle daño o explotarla. La lealtad, es hacer las cosas con las que una persona se compromete aun cuando las circunstancias cambian, es una obligación que se tiene con los demás que desarrolla con- 
fianza, e indica una cualidad interna de rectitud y fidelidad a las promesas que se hacen entre personas y organizaciones (Torres, 2007).

La Asociación Americana de Marketing (AMA), en 2004 estableció un código de ética con las siguientes reglas:

1) Responsabilidad del directivo: se debe de aceptar la responsabilidad y las consecuencias de sus actos, y garantizar que todas sus acciones y decisiones estén dirigidas para identificar, servir, y satisfacer a todos los clientes, organizaciones y sociedad.

2) Honestidad e integridad: se debe de impulsar y desarrollar la integridad, el honor y dignidad de la profesión.

3) Derechos y deberes en el proceso de intercambio comercial: los consumidores deben recibir productos y servicios adecuados al uso que se requiere, comunicaciones no engañosas, métodos adecuados de compensación por algún tipo de incumplimiento, y un sistema de manejo de quejas y sugerencias.
4) Relaciones Organizacionales: los empresarios deben estar conscientes de la capacidad que tienen para influir en otras personas dentro de la empresa, y por eso su comportamiento debe ser totalmente ético.

(Cruz, 2007)

En relación a esta normativa de la AMA, se establecen un conjunto de valores éticos como la honestidad, responsabilidad, equidad, respeto, transparencia, y ciudadanía, y al cumplir todos estos elementos, se puede decir que son acciones éticas de marketing en las empresas (Cruz, 2007).

\section{ÉTICA EN}

\section{NEUROMARKETING Y} MARKETING SENSORIAL

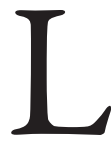
a dimensión de la ética en el neuromarketing es uno de los más grandes y sensibles retos en relación a su aplicación en el campo de la investigación de mercados. Desde que el neuromarketing tuvo su origen, surgieron controversias éticas entre los investigadores sobre la metodología aplicada a estas técnicas, ya que algunos argumentan que los sujetos de estudio están desconfiando de estas nuevas tecnologías, y otros afirman que es el descubrimiento del "botón de compra" en el cerebro humano (Pop et al., 2014).

Los abogados del neuromarketing alegan que las neurociencias son benéficas tanto para empresas como para sus clientes, debido a que se puede saber con cierta exactitud el deseo de los productos que los clientes tienen, pero también existen críticas que argumentan que las neurociencias limitan y comprometen la habilidad del consumidor al momento de tomar decisiones, y es ahí donde entra el impacto de las dimensiones éticas. Las técnicas y herramientas que las neurociencias aplican a los consumidores pueden resultar en una manipulación favorable o desfavorable, y los investigadores se enfrentan a un reto ético por el hecho de que les aseguran a los clientes que es una manipulación positiva, racional y formativa para las personas y la sociedad en general. Se cree que el término "manipulación" en el neuromarketing es utilizado cuando es conveniente para las empresas (Pop et al., 2014).

El concepto de neuroética surgió en el año 2002 como 
una disciplina, basada en un antecedente de bioética médica, filosofía, ley, y neurociencia. Todas estas prácticas constituyen el trabajo actual de la neuroética, y los autores Fukushi \& Sakura, citados en Sebastián (2014), la definen como el estudio de una serie de problemas profesionales y éticos, problemas relacionados con un sistema de valores neurobiológicos, y las implicaciones sociales de la investigación neurocientífica que presentan todos esos elementos.

Roskies, citado en Sebastián (2014), define la neuroética partiendo de la ética de la neurociencia, y la neurociencia de la ética. Hoy en día la ética de la neurociencia se divide en dos campos que tratan de responder a varias preguntas. El primer campo considera todos los aspectos éticos que se requieren para la implementación de estudios neurocientíficos, mientras que el segundo campo trata directamente con las cuestiones éticas, sociales e impacto legal para dichos estudios. Según Roskies, el segundo campo ha atraído el interés de los investigadores, ya que tiene un fuerte vínculo en el entendimiento del cere- bro humano, un gran número de posibilidades para cambiar la sociedad en la que se vive, y de cierta manera proveer predictibilidad (Sebastián, 2014).

La Asociación de Neuromarketing, Ciencias y Negocios (NMSBA), publicó un código de ética para la aplicación de neurociencias en aspecto de negocios, con el objetivo de asegurar los más altos estándares éticos en la industria de la investigación de neuromarketing.

\section{Ventas}

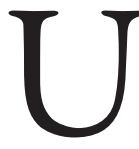

no de los resultados del marketing, es el intercambio, y se refiere a cuando las personas proporcionan algo para recibir otra cosa que prefieren (Lamb et al., 2011). Partiendo del intercambio, las ventas han sido a lo largo del tiempo una manera de realizar transacciones entre dos partes, y el intercambio de productos y servicios por un valor monetario o de otra índole. Una definición general de las ventas es traspasar a otra persona o parte la propiedad de un bien o servicio por un precio convenido (Lamb et al., 2011).
Las ventas y el marketing están muy relacionados, y las ventas tienen como objetivo vender los productos o servicios que las empresas ofrecen, tomando en cuenta todas la investigación que se realiza para conocer las necesidades de los consumidores (Jobber \& Lancaster, 2012).

\section{Mezcla PROMOCIONAL}

T a mezcla promocional se puede definir como la integración de herramientas de publicidad, relaciones públicas, promoción de ventas y ventas personales, que la gerencia de una empresa cree adecuada para satisfacer las necesidades del mercado meta y alcanzar las metas generales de la organización (Lamb et al., 2011).

La estrategia promocional es un plan para el uso óptimo de la mezcla promocional (publicidad, relaciones públicas, promoción de ventas y ventas personales), en el cual se determinan los objetivos de la estrategia promocional con base en los objetivos generales del mix de marketing (plaza, promoción, precio y producto). 
VENTAS DENTRO DE LA MEZCLA PROMOCIONAL

T $\begin{aligned} & \text { as ventas personales } \\ & \text { se definen como una } \\ & \text { situación de compras }\end{aligned}$ que incluye una comunicación personal que es pagada, entre dos personas, en un intento por influir entre ellas. La venta personal y otros elementos de la mezcla promocional, dependen cada vez más del internet, por lo que la mayoría de las empresas utilizan sus sitios web para la atracción de consumidores potenciales que buscan informarse de los productos y servicios que desean adquirir (Lamb et al., 2011).

La promoción de ventas es una herramienta que se utiliza para estimular incrementos inmediatos en la demanda, y que es a corto plazo. Consiste en todas las actividades de marketing, ajenas a los componentes de la mezcla promocional, que tienen como objetivo estimular todas las compras de los consumidores, así como la eficacia de los concesionarios. La investigación muestra que la promoción de ventas es complementaria a la publicidad, ya que ofrece respuestas más rápidas de ventas, y puede dirigirse a los consumidores finales, clientes comerciales, o empleados de una empresa (Lamb et al., 2011).

\section{Metodología}

T a investigación que se realizó fue de tipo exploratoria y causa, utilizando un enfoque mixto cualitativo y cuantitativo. La perspectiva cualitativa utiliza la recolección de datos sin utilizar una medición numérica, para poder afinar preguntas de investigación en el proceso de interpretación (Hernández et al., 2010). Para esta investigación se formalizó una sesión focal a consumidores de la empresa sujeta al estudio.

El enfoque cuantitativo recolecta datos para la comprobación de hipótesis, basado en la medición numérica y análisis estadístico que establecen patrones de comportamiento y prueban teorías (Hernández et al., 2010). Se desarrolló un análisis de las ventas unitarias de la empresa del sector alimentario en un periodo de tiempo determinado,

\section{OBjetivos DE INVESTIGACIÓN}

1) Analizar el comportamiento de las ventas unitarias dentro de las unidades de negocio sujetas a un olor implementado, en un periodo de tres meses.

2) Comparar la variación en las ventas unitarias entre las unidades de venta expuestas al olor implementado, versus las unidades de negocio no expuestas al olor, en un periodo de tres meses.

Hipótesis de INVESTIGACIÓN $\tau\left[\begin{array}{l}1: \text { La presencia de } \\ \text { un olor como he- } \\ \text { rramienta de marke- }\end{array}\right.$ ting sensorial en las unidades de medición incrementará un $10 \%$ las ventas unitarias de toda la línea de productos.

$\mathbf{H}^{2}$ : Las ventas en una unidad de negocio con presencia de un olor como herramienta de marketing sensorial, serán mayores a las de una unidad de negocio que no presenta el olor. 
EXPERIMENTO SENSORIAL Olfativo (FASE CUALITATIVA)

$\mathrm{P}$ ara la fase cualitativa se llevó a cabo un grupo de enfoque. La sesión de grupo o grupo de enfoque es una entrevista no estructurada y de forma natural, la cual se lleva a cabo por un moderador capacitado para el grupo sujeto del estudio. El objetivo principal de una sesión de grupo o grupo de enfoque es obtener información del grupo de personas del mercado investigado que sean de interés para el investigador, y que es recopilada por la discusión fluida que sostiene el grupo. Las sesiones de grupo son la parte más importante de la investigación cualitativa, y su valor se da en los hallazgos que el grupo investigado aporta (Malhotra, 2008).

El moderador debe poseer ciertas habilidades en una sesión de grupo o grupo de enfoque como amabilidad y firmeza, ser permisivo y mantenerse alerta a las señales del grupo, estar involucrado, animar a los participantes a ser específicos en los comentarios, motivar a los participantes que no se involucran a participar, ser flexible y poder modificar el esque- ma en caso de ser necesario, y sensible para poder guiar la sesión en un nivel intelectual y emocional (Malhotra, 2008).

La sesión de grupo se realizó el martes 29 de septiembre del 2015 para identificar puntos fundamentales de la empresa pastelera, en relación a la percepción general del consumidor, aspectos de limpieza, arreglo y aromas, y su competencia más fuerte en el mercado. Se seleccionaron ocho participantes con un nivel socioeconómico medio, de los cuales cinco fueron mujeres $y$ tres hombres, ya que el mercado principal de la empresa es femenino.

La sesión se llevó a cabo en una Cámara de Gesell, donde los participantes del estudio fueron grabados por medio de dos cámaras de video y un micrófono de audio durante toda la sesión para poder capturar todos los momentos importantes que surgieran.

Se hizo un experimento en dos fases a cada uno de los participantes de la sesión de grupo. En la fase uno se presentó a cada uno de los participantes seis aromas diferentes sin que supieran el nombre del aroma (1) Fresas, 2) Uvas silvestres,
3) Muffin, 4) Frutos rojos, 5) Crema catalana), y se les pidió que olieran cada uno de ellos e imaginaran una pastelería ideal, y la sensación provocada por cada uno de los aromas. En la segunda fase se les dijo el nombre de cada uno de los aromas que olieron y se les presentó una serie de imágenes de la empresa pastelera sujeta al estudio, y se les pidió que asociaran los tres olores que más vincularon a dicha empresa.

Finalmente se les proporcionó una lista de cuatro aromas diferentes a los del experimento, para que los ordenaran por orden de importancia.

\section{RESUlTADOS Y \\ Hallazgos Del EXPERIMENTO SENSORIAL Olfativo}

\section{SíNTESIS DE LAS IDEAS} PRINCIPALES DE LA SESIÓN DE GRUPO

n la tabla 7 de asocia-
ción de palabras se
muestran las respuestas que los asistentes sujetos de estudio de la sesión de grupo indicaron al momento de llevarla a cabo en relación a la limpieza, el arreglo y los aromas percibidos. 
Tabla 7: Atributos de la empresa pastelera y de su competencia

Hallazgos adicionales (ARREGLO, LIMPIEZA, AROMAS)

Todos los participantes de la sesión de grupo conocen a la empresa pastelera sujeta al estudio de investigación, pero no percibieron ningún aroma en la misma (empresa 3), mientras que algunos de los participantes conocen a la empresa 4 , y otros no.

Una de las participantes comentó al momento de hablar de los aspectos de las empresas pasteleras, que la empresa en su logotipo genera confusión ya que no tenía claro que animal y colores lo componían. El motivo de su visita a la empresa 1 fue debido a que en la empresa 3, sujeta al estudio, no había encontrado el producto que buscaba.

Otra de las participantes hizo una comparación entre la empresa sujeta al estudio, empresa 3, y empresa 5, argumentando que la empresa 5 es una pastelería tradicional con buenos pasteles (mejores que otros), algo caros, y no todas las sucursales están homogenizadas, y la empresa 3, tiene el mismo tipo de pasteles caseros pero con sabores diferentes, haciéndole falta más variedad.

\begin{tabular}{|c|c|c|}
\hline & Atributos Destacados & $\begin{array}{l}\text { Inconvenientes de las } \\
\text { Diferentes Empresas }\end{array}$ \\
\hline Empresa 1 & $\begin{array}{l}\text { Buenas condiciones. } \\
\text { La limpieza muy bien. } \\
\text { No se ve nada raro. } \\
\text { Bastante higiene de las em- } \\
\text { pleadas para tomar los paste- } \\
\text { les. }\end{array}$ & $\begin{array}{l}\text { Llama la atención que están } \\
\text { enrejadas las chicas que } \\
\text { atienden. } \\
\text { No tiene acceso a los pas- } \\
\text { teles. } \\
\text { Caros. } \\
\text { Poco atractivo en cuanto } \\
\text { fachada y colores. }\end{array}$ \\
\hline Empresa 2 & $\begin{array}{l}\text { Muy cálido y accesible. } \\
\text { Pasteles muy al alcance y tú } \\
\text { escoges. } \\
\text { Es tradicional. } \\
\text { Huele muy rico, a pan, a hor- } \\
\text { no. } \\
\text { Buena imagen y arreglo. } \\
\text { El logotipo llama mucho la } \\
\text { atención. } \\
\text { Muy limpio. } \\
\text { Buena atención de los vende- } \\
\text { dores. }\end{array}$ & $\begin{array}{l}\text { Es cara. } \\
\text { No percibo ningún olor. }\end{array}$ \\
\hline $\begin{array}{l}\text { Empresa } 3 \\
\text { (Empresa } \\
\text { Pastelera } \\
\text { sujeta al } \\
\text { estudio) }\end{array}$ & $\begin{array}{l}\text { Precio accesible. } \\
\text { Está rico sin ser espectacular } \\
\text { el sabor. } \\
\text { Se ve limpio pero sin exagerar. } \\
\text { Tienen y venden muchas cosas } \\
\text { que en otros no encuentras. } \\
\text { Se me hacen limpios. }\end{array}$ & $\begin{array}{l}\text { No tan limpios todos los } \\
\text { locales. } \\
\text { Son locales chicos. } \\
\text { Las rejas no están bien pin- } \\
\text { tadas. } \\
\text { Sensación de entrada de frial- } \\
\text { dad, de distancia. } \\
\text { Logotipo frío. } \\
\text { Ningún olor. }\end{array}$ \\
\hline Empresa 4 & $\begin{array}{l}\text { Los arreglos en general se ven } \\
\text { cálidos. } \\
\text { Todo muy limpio. } \\
\text { Es más cálido que otras. }\end{array}$ & $\begin{array}{l}\text { Ningún olor. } \\
\text { No recuerdo olores. }\end{array}$ \\
\hline Empresa 5 & $\begin{array}{l}\text { Se ve limpio. } \\
\text { Hay una persona que abre el } \\
\text { refrigerador y toma el pastel } \\
\text { deseado por el cliente. } \\
\text { Siempre está ahí el "yo te lo } \\
\text { saco". }\end{array}$ & $\begin{array}{l}\text { Limpieza no igual en todas. } \\
\text { El problema es que es muy } \\
\text { caro. } \\
\text { No todos están homogeni- } \\
\text { zados. } \\
\text { Pintado del mismo color que } \\
\text { el logo, se pierde. } \\
\text { Muy desorganizado el am- } \\
\text { biente. } \\
\text { No percibí ningún olor igual } \\
\text { que en la Zarza. }\end{array}$ \\
\hline
\end{tabular}

Fuente: Elaboración propia. 
DESCRIPCIÓN DE PASTELERÍA IDEAL CON AROMAS "NO" IDENTIFICADOS POR LOS PARTICIPANTES

n la tabla 8 se muestran 4 los aromas presentados: 1) Fresa, 2) Uvas silvestres, 3) Muffin, 4) Frutos rojos, 5) Crema catalana, y se agruparon las respuestas de cada uno de los participantes en relación a la pastelería ideal que se imaginaron al oler los cinco diferentes aromas.

\section{Hallazgos adicionales EN LA DESCRIPCIÓN DE PASTELERÍA IDEAL CON AROMAS "NO" IDENTIFICADOS POR LOS PARTICIPANTES}

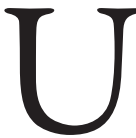

no de los participantes mencionó que el aroma 1 (fresa) lo hostiga mucho si permanece un largo periodo de tiempo oliéndolo, y otro de los participantes dijo que no se imagina una pastelería con aroma 1. Ver tabla 8.

IDENTIFICACIÓN Y RECONOCIMIENTO DE LOS Aromas

n esta fase se les dijo $\checkmark$ a los participantes de Lla sesión de grupo el nombre y tipo de aroma que
Tabla 8: Pastelería ideal con aromas no identificados

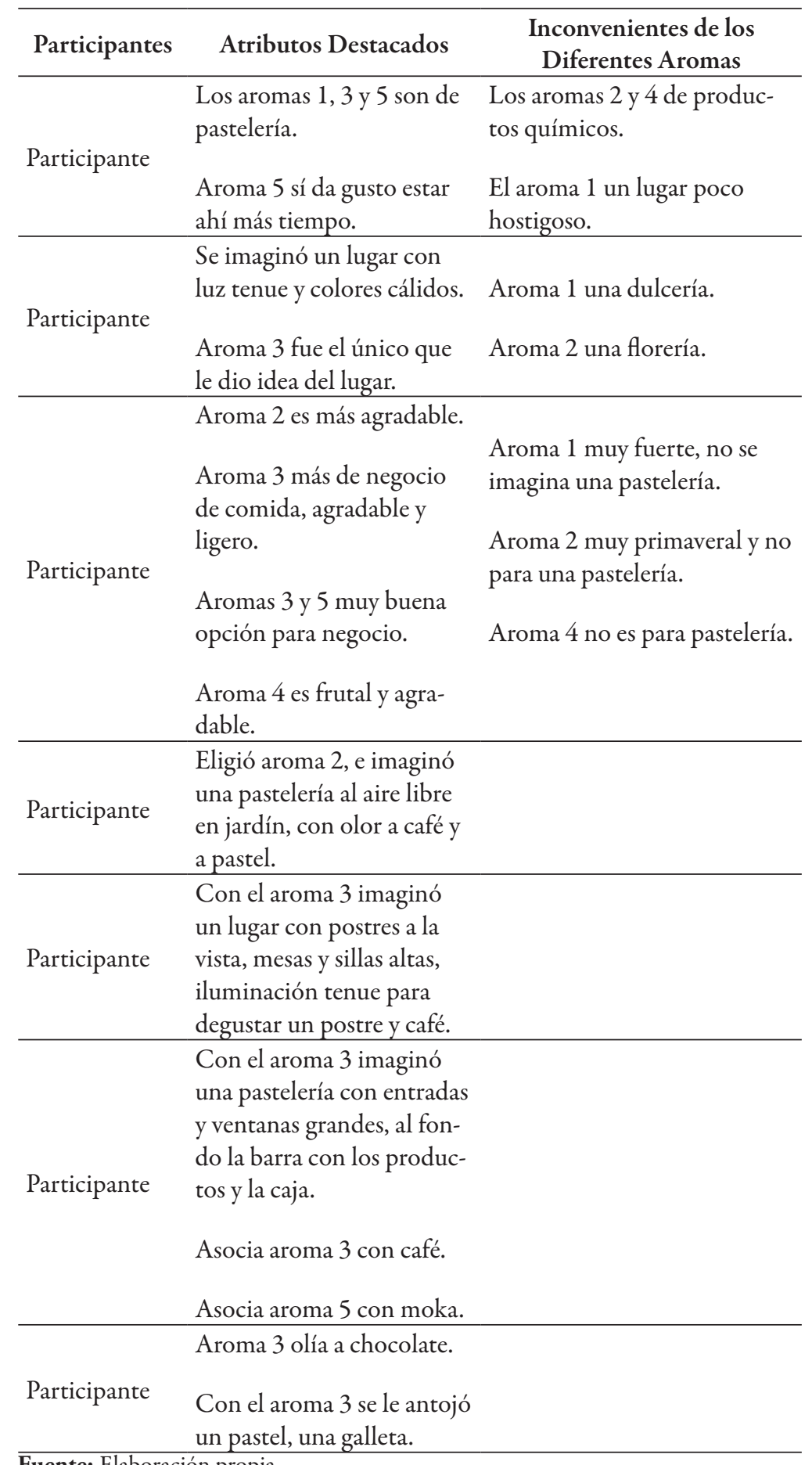


habían olido y se les mostraron imágenes de la empresa sujeta al estudio (empresa 3) para que escogieran tres de los cinco aromas que asociaran con la empresa. Ver tabla 9.

Aromas Presentados:

1) Fresa, 2) Uvas Silvestres, 3) Muffin, 4) Frutos Rojos, 5) Crema catalana.

Tabla 9: Aromas elegidos por los participantes al ver las imágenes de la empresa pastelera y al asociar la marca con el aroma

\begin{tabular}{ll}
\hline & Aromas elegidos \\
\hline Participante & $1,2,5$ \\
\hline Participante & $1,4,5$ \\
\hline Participante & $2,4,5$ \\
\hline Participante & $2,3,5$ \\
\hline Participante & $2,3,4$ \\
\hline Participante & $2,3,5$ \\
\hline Participante & $2,4,5$ \\
\hline Participante & $1,2,4$ \\
\hline
\end{tabular}

Fuente: Elaboración propia.

La tabla muestra que los aromas elegidos por los participantes una vez que se les dijo el nombre y tipo de aroma, fueron totalmente diferentes a los aromas elegidos cuando se les pidió que imaginaran una pastelería ideal con alguno de los aromas, y esto es debido a que cada participante asoció la marca de la empresa pastelera sujeta al estudio, empresa 3, con los aromas 2, 4, y 5, y con los atributos de los locales y logotipo.

El aroma 3, el cual en un inicio la mayoría de los participantes mencionó como ideal, fue elegido solo por tres de los ocho participantes.

Otros aromas ajenos a los expuestos que algunos de los participantes mencionaron al ver las imágenes de la empresa pastelera sujeta al estudio, empresa 3, fueron: merengue, pan horneado, moras y pastel.

\section{IMPLEMENTACIÓN DEL} EXPERIMENTO SENSORIAL Olfativo (Fase CUANTITATIVA)

n esta fase del experi-1 mento se seleccionaron tres sucursales de la empresa del sector alimentario para la implementación, y fueron divididas por nivel socioeconómico alto (Sonata), medio (San Alejandro) y bajo (Xilotzingo), en diferentes puntos de la zona metropolitana de Puebla. El experimento se llevó a cabo en dos periodos de tiempo y tuvo una duración de seis meses que abarcó de septiembre a noviembre de 2015 , y de enero a marzo de 2016; diciembre quedó excluido debido a que es temporada alta para la empresa, y en el caso de Sonata, se excluyó septiembre y octubre debido a que durante esos meses existió actividad promocional y lanzamiento de un nuevo producto. Los datos de estos meses fueron sustituidos por los inmediatos anteriores (julio y agosto), más el mes de noviembre debido a que a mediados de este mes la actividad promocional estaba finalizando y el nuevo producto había concluido la etapa de penetración.

Durante el primer periodo se analizó el comportamiento de las ventas unitarias de cada una de las tres sucursales sin la presencia de ningún aroma de los que fueron seleccionados en la sesión de grupo que se realizó en septiembre de 2015. En el segundo periodo del experimento se aplicó cada uno de los aromas a las mismas sucursales del primer periodo, cambiando un aroma por mes hasta lograr que los tres estuvieran presentes en las sucursales seleccionadas, y se analizó el comportamiento de las ventas unitarias.

Los aromas que se aplicaron a cada una de las sucursales durante el segundo periodo 
del experimento fueron los siguientes:

- Uvas Silvestres:

$\checkmark$ Enero: Xilotzingo

$\checkmark$ Febrero: Sonata

$\checkmark$ Marzo: San Alejandro

- Crema Catalana:

$\checkmark$ Enero: Sonata

$\checkmark$ Febrero: San Alejandro

$\checkmark$ Marzo: Xilotzingo

Adicionalmente, se analizó el comportamiento de las ventas unitarias a tres sucursales más de la empresa que no formaron parte del experimento, las cuales fueron dividas con el mismo criterio socioeconómico y durante el mismo periodo de seis meses, con el objetivo de identificar si había un flujo normal o variación de las ventas.

\section{Mecanismo de Difusión DE LOS Aromas}

$\mathrm{P}$ ara efectos de la difusión del aroma que se implementó en las sucursales sujetas al experimento sensorial, se empleó el aroma Nebulizer Mini, el cual es un micronebulizador que funciona con un sistema de pulveri- zación que emite partículas olfativas por medio de una bomba de aire que transforma el aroma de estado líquido a gaseoso. Este difusor funciona por medio de enchufe eléctrico, utiliza una carga de perfume de 600 mililitros con una cobertura de hasta 300 metros, y un peso de 1.63 kilogramos.

\section{RESUltados Y}

Hallazgos Del IMPACTO DE LAS VENTAS UNITARIAS

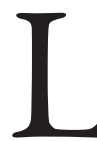
as tablas 10 y 11 indican el comportamiento de las ventas unitarias de la empresa al finalizar los dos periodos del experimento.

En la tabla 15 se observa que las ventas de las sucursales sin aroma del primer periodo del experimento (septiembre, octubre y noviembre) tuvieron un flujo normal con una mínima variación por mes. La sucursal de Sonata es la única que presenta una diferencia dispersa entre los meses de julio y agosto de 2015, debido a la actividad mercadológica e introducción de un nuevo producto que ya se explicó con anterioridad. Los meses de agosto y noviembre de la misma sucursal muestran una actividad normal en las ventas.
En la tabla 16, las ventas del segundo periodo (enero, febrero y marzo) del experimento presentan un incremento considerable por mes como resultado de la implementación de cada uno de los aromas, a diferencia de las ventas del primer periodo en las mismas sucursales. 
Tabla 10: Resultados de Ventas en Sucursales sin Aroma Implementado

\begin{tabular}{|c|c|c|c|c|}
\hline & \multicolumn{3}{|c|}{ Sucursales sin Aroma Implementado } & \multirow[b]{3}{*}{ TOTAL VENTAS } \\
\hline & \multicolumn{3}{|c|}{ Ventas Unitarias por Mes (unidades) } & \\
\hline & Septiembre (2015) & Octubre (2015) & Noviembre(2015) & \\
\hline \multirow[t]{2}{*}{ Xilotzingo } & 774 & 696 & 760 & 2230 \\
\hline & Septiembre (2015) & Octubre (2015) & Noviembre(2015) & \\
\hline \multirow[t]{2}{*}{ San Alejandro } & 1798 & 1788 & 1830 & 5416 \\
\hline & Julio (2015) & Agosto (2015) & Noviembre (2015) & \\
\hline Sonata & 1223 & 2391 & 2179 & 5793 \\
\hline
\end{tabular}

Fuente: Elaboración propia.

Tabla 11: Resultados de Ventas en Sucursales con el Aroma Implementado

\begin{tabular}{|c|c|c|c|c|}
\hline & \multicolumn{3}{|c|}{ Sucursales con Aroma Implementado } & \multirow[b]{3}{*}{ TOTAL VENTAS } \\
\hline & \multicolumn{3}{|c|}{ Ventas Unitarias por Mes (unidades) } & \\
\hline & Enero $(2016)$ & Febrero (2016) & $\operatorname{Marzo}(2016)$ & \\
\hline $\begin{array}{l}\text { Aromas Implemen- } \\
\text { tados }\end{array}$ & Uvas Silvestres & Frutos Rojos & Crema Catalana & \\
\hline \multirow[t]{2}{*}{ Xilotzingo } & 847 & 857 & 848 & 2552 \\
\hline & Frutos Rojos & Crema Catalana & Uvas Silvestres & \\
\hline \multirow[t]{2}{*}{ San Alejandro } & 2023 & 1840 & 1875 & 5738 \\
\hline & Crema Catalana & Uvas Silvestres & Fruto Rojos & \\
\hline Sonata & 2163 & 2040 & 2141 & 6344 \\
\hline
\end{tabular}

Fuente: Elaboración propia

El promedio de incremen- fue del $9.97 \%$, y en la tabla 12 to en las ventas unitarias de las se puede observar que la sutres sucursales al final de los cursal de Xilotzingo, ubicada dos periodos del experimento en una zona de clase baja den- tro de la zona metropolitana de Puebla, tuvo el mayor porcentaje de incremento en las ventas con un $14.44 \%$. 
Tabla 12: Porcentaje de variación en las ventas unitarias después del experimento con aromas

\begin{tabular}{|c|c|c|}
\hline \multicolumn{3}{|c|}{$\%$ de Variación en las ventas después del experimento } \\
\hline Xilotzingo & \multicolumn{2}{|c|}{$14.44 \%$} \\
\hline San Alejandro & \multicolumn{2}{|c|}{$5.95 \%$} \\
\hline Sonata & \multicolumn{2}{|c|}{$9.51 \%$} \\
\hline & Promedio & $9.97 \%$ \\
\hline
\end{tabular}

Fuente: Elaboración propia

Las tablas 13 y 14 indican el comportamiento de las ventas unitarias en las sucursales que no formaron parte del experimento y que fueron divididas bajo el mismo criterio socioeconómico, siendo Mayorazgo clase baja, El Vergel clase media, y Santa Fe clase alta. El análisis se realizó en los mismos meses que las sucursales sujetas al experimento, y se observa que las ventas de las tres sucursales mostraron una mínima variación a diferencia de las sucursales que participaron en el experimento.

Tabla 13: Resultados de las ventas en sucursales que no fueron sujetas al experimento ${ }^{1}$

\begin{tabular}{ccccc}
\cline { 2 - 4 } & \multicolumn{2}{c}{ Sucursales no sujetas al experimento $^{\mathbf{1}}$} & \\
\cline { 2 - 4 } & \multicolumn{2}{c}{ Ventas unitarias totales por mes } & \\
\cline { 2 - 4 } & $\begin{array}{c}\text { Septiembre } \\
(2015)\end{array}$ & $\begin{array}{c}\text { Octubre } \\
(2015)\end{array}$ & $\begin{array}{c}\text { Noviembre } \\
(2015)\end{array}$ & Total ventas \\
\cline { 2 - 4 } Mayorazgo & 1155 & 1175 & 1141 & 3471 \\
\hline El Vergel & 819 & 857 & 858 & 2534 \\
\hline Santa Fe & 1490 & 1309 & 1249 & 4048 \\
\hline
\end{tabular}

Fuente: Elaboración propia 
Tabla 14: Resultado de las Ventas en Sucursales que no fueron Sujetas al Experimento ${ }^{2}$

\begin{tabular}{ccccc} 
& \multicolumn{2}{c}{ Sucursales no sujetas al experimento ${ }^{2}$} & \\
\cline { 2 - 4 } & \multicolumn{2}{c}{ Ventas unitarias totales por mes } & \\
\cline { 2 - 4 } & Enero (2016) & $\begin{array}{c}\text { Febrero } \\
(2016)\end{array}$ & $\begin{array}{c}\text { Marzo } \\
(2016)\end{array}$ & Total ventas \\
\hline Mayorazgo & 1138 & 1102 & 1161 & 3401 \\
\hline El Vergel & 850 & 817 & 902 & 2569 \\
\hline Santa Fe & 1328 & 1393 & 1385 & 4106 \\
\hline
\end{tabular}

Fuente: Elaboración propia

La tabla 15 indica que en entre las tres sucursales que no el periodo de los seis meses el fueron parte del experimento, comportamiento de las ventas y un decremento del $2.02 \%$ en fue casi uniforme, con un pro- la sucursal de Mayorazgo (clamedio de $0.27 \%$ de aumento se baja).

Tabla 15: Porcentaje de Variación en las Ventas Unitarias en Sucursales que no fueron Sujetas al Experimento

\begin{tabular}{ccc}
\hline \% de Variación en las ventas después del experimento \\
\hline Mayorazgo & $-2.02 \%$ & \\
\hline El Vergel & $1.38 \%$ & \\
\hline Santa Fe & $1.43 \%$ \\
\hline \multicolumn{3}{c}{$0.27 \%$} \\
\hline
\end{tabular}

Fuente: Elaboración propia

De los tres aromas implementados a cada una de las sucursales que participaron en el experimento, se puede ver en la tabla 16 que el aroma de frutos rojos fue el que mayor impacto tuvo en las ventas durante el segundo periodo del experimento con un total de
5021 unidades vendidas entre las tres sucursales.

La sucursal de Xilotzingo (clase baja) fue la que presentó el mayor crecimiento de las ventas con 857 unidades vendidas en el mes de febrero de 2016. Ver tabla 11. 
Tabla 16: Suma de las ventas unitarias unificadas por aroma implementado

\begin{tabular}{cccc}
\hline & \multicolumn{3}{c}{ Ventas por Aroma Implementado (unidades) } \\
\hline $\begin{array}{c}\text { Aromas } \\
\text { Implementados }\end{array}$ & Uvas Silvestres & Frutos Rojos & Crema Catalana \\
\hline Xilotzingo & 847 & 857 & 848 \\
\hline San Alejandro & 1875 & 2023 & 1840 \\
\hline Sonata & 2040 & 2141 & 2163 \\
\hline TOTAL VENTAS & 4762 & 5021 & 4851 \\
\hline
\end{tabular}

Fuente: Elaboración propia.

\section{Conclusiones}

$1 \begin{aligned} & \text { partir de los datos } \\ & \text { analizados derivados } \\ & \text { del experimento se }\end{aligned}$ encontraron los siguientes hallazgos:

- Los participantes de la sesión de grupo eligieron aromas diferentes a los que habían seleccionado previamente en la dinámica de imaginar una pastelería ideal, y fue debido a que al observar las imágenes de la empresa una vez que se les mostró, asociaron la marca y el logotipo con los aromas (Frutos rojos, Uvas silvestres y Crema catalana).

- La sesión de grupo permitió por medio de los participantes la selección de los tres aromas a implementar en las sucursales sujetas al experimento sensorial olfativo.

- Existe un incremento en las ventas unitarias de $9.97 \%$ entre las mismas sucursales que participaron en el experimento sin aroma en el primer periodo (septiembre, octubre y noviembre de 2015) y con aroma en el segundo periodo (enero, febrero y marzo de 2016).

- El aroma que más incide en las tres sucursales a las que se les implementó los aromas fue frutos rojos, con un total de 5021 unidades vendidas durante el segundo periodo del experimento.

- Las tres sucursales que participaron en el experimento con los aromas implementados tuvieron en promedio un incremento del 9.97\% durante el segundo periodo, mientras que las sucursales que no formaron parte del experimento solo tuvieron un incremento del $0.27 \%$ en el mismo periodo.

- La sucursal de Xilotzingo (clase baja) fue la que tuvo el mayor porcentaje en el incremento de las ventas de las tres sucursales con aromas con un $14.44 \%$.

- Con base en todo el análisis realizado en esta investigación, se aceptan las hipótesis planteadas.

- Debido a la innovación en este tipo de experimentos, es importante tener en cuenta las implicaciones éticas de las empresas que aplican estas herramientas sensoriales.

\section{BIBLIOGRAFÍA}

Alfaro, K. (2012). Ética y Psicología. Estado de México: Red Tercer Milenio.

Álvarez, R. (2011). Neuromarketing: Fusión Perfecta. Madrid: Prentice Hall.

Bonadeo, M. (2005). Odotipo: historia natural del olfato y su función en la identidad de marca. (Tesis de doctorado, Facultad de Comunicación, Universidad Austral, Buenos Aires). Recuperado de www.mar- 
tinbonadeo.com.ar/pdf/ Odotipo.pdf

Cruz, I. (2007). El Marketing y las Conductas Éticas: Regulación y Autorregulación. Mediterráneo Económico, 11.

Cuevas, R. (2005). La construcción de la ética de la empresa de los negocios, Primera parte. Las formas a partir de la adopción de la ética. Contaduría y Administración, 216.

Currás, R. (2012). Antecedentes y consecuencias de la identificación del consumidor con la empresa: Revisión Conceptual y Clasificación. Revista Cuadernos de Administración. Bogotá (Colombia), Vol. 25 (44): 93-115. Acceso: http://132.248.9.34/hevila/Cuadernosdeadministracion/2012/vol25/ no44/4.pdf

Dani, V, Pabalkar, V. (2013). Branding through Sensory Marketing. Journal of Scientific Research, Vol. 2 Iss 11.

Gómez, C. (2012). La identidad olfativa: Una estrategia invisible y silenciosa. Revista Virtual Universidad Católica del Norte. No. 37, (septiembre-diciembre de 2012, Colombia). Acceso: [http://revistavirtual.ucn. edu.co/]

Guzmán, Y, et al. (2010). El Fascinante mundo de los olores. Revista de Divulgación Cientifica y Tecnológica de la Universidad Veracruzana. Vol. XXII, n ${ }^{\circ} 1$. Disponible en: https://www. uv. $\mathrm{mx} /$ cienciahombre/revistae/vol23num 1/articulos/olores/

Hawkins, Del I et al. (2004). Comportamiento del consumidor. Construyendo estrategias de marketing. $9^{\circ}$ Edición. México: Ed. Mc Graw Hill.

Hultén, B. (2011). "Sensory marketing: the multi-sensory brand-experience concept", European Business Review, Vol. 23 Iss 3 pp. 256 273. Permanent link to this document: http://dx.doi. org/10.1108/09555341111 130245

Jiménez, S, et al. (2010). Importancia de los valores para el ejercicio ético de la profesión. Pachuca, México: Universidad Autónoma del Estado de Hidalgo.

Jobber, D, Lancaster, G. (2012). Administración de ventas. México: Pearson Education.

Kotler, P, Keller, K. (2012). Dirección de Marketing. México: Pearson Education.

Kotler, P, Armstrong, G. (2008). Fundamentos de Marketing. México: Pearson Educación.

Lamb, C, et al. (2011). Marketing. México: CENGAGE Learning.

Maldonado, J. (2008). Factores que Influyen en la Conducta del Consumidor. "Una Aproximación desde las Ciencias Sociales. Trabajo presentado para el Premio Nacional de Investigación del Colparmex. Universidad Modelo. Disponible en: http://www. colparmex.org/Revista/ Art 10/50.pdf

Maldonado, O, et al. (2012). El sistema olfatorio: el sentido de los olores. Revista de Divulgación Cientifica y Tecnológica de la Universidad Veracruzana. Vol. XXV, n². Disponible en: http://www.uv.mx/ cienciahombre/revistae/ vol25num $2 /$ articulos/sistema/ 
Malhotra, N. (2008). Investigación de mercados. México: Pearson Educación.

Martínez, J. (2011). "Evolución del marketing: desde el egocentrismo a la orientación al consumidor", en Contribuciones a la Economia, diciembre 2011, en http://www.eumed.net/ ce/2011b/

Moliner, M, Cervera, A. (2005). Historia y Teoría del Marketing: Documento Base 1. Universidad de Alicante, Universidad Politécnica de Valencia, Universidad de Valencia.

Moliner, M, Cervera, A. (2005). Historia y Teoría del Marketing: Documento Base 2. Universidad de Alicante, Universidad Politécnica de Valencia, Universidad de Valencia.

Pop, N., Dabija, D., \& Iorga, A. (2014). Ethical Responsibility of Neuromarketing Companies in Harnessing the Market Research - A Global Exploratory Approach. Amfiteatru Economic, 16(35).

ProMéxico, (2012). Industria de Alimentos Procesados. En http://mim. promexico.gob.mx/work/
sites/mim/resources/LocalContent/72/2/Alimentos_procesados_ES.pdf. México: ProMéxico.

ProMéxico, (2013). Alimentos Procesados. En http:// embamex.sre.gob.mx/rusia/images/stories/Comercio/procesadospromexico. pdf. México: ProMéxico.

ProMéxico, (2014). Alimentos Procesados. En http:// mim.promexico.gob.mx/ JS/MIM/PerfilDelSector/AlimentosProcesados/080914_DS_Alimentos_Procesados_ES.pdf). México: ProMéxico.

Revista Énfasis, (2012). La industria de alimentos en México. Recuperado el 30 Noviembre 2015, en http:// www.alimentacion.enfasis. com/articulos/63590-laindustria-alimentos-mexico Ruiz, P. (2011). Comportamiento Ético / No Ético en la Empresa: Revisión de los Enfoques Propuestos en la Literatura para la Mejora de su Comprensión. Facultad De Ciencias Sociales De Cuenca. Recuperado de http://www.uclm.es/ CU/csociales/DocumentosTrabajo
Hernández, R, et al. (2010). Metodología de la Investigación. México: McGraw Hill.

Schiffman, L, Lazar. L. (2010). Comportamiento del consumidor. México: Pearson Educación.

Schiffman, L, Kanuk, L. (2005). Comportamiento del consumidor. $8^{\circ}$ Edición. México: Ed. Pearson Educación.

Sebastian, V. (2014). Neuromarketing and Neuroethics. Procedia-Social and Behavioral Sciences, 127, 763-768. http:// dx.doi.org/10.1016

Sheth, J, et al. (1988). Marketing Theory: evolution and evaluation. Canada: John Wiley \& Sons, Inc.

Torres, F. (2007). Cuestiones Éticas en el Marketing. VIII Congreso Nacional e Internacional de Administración, 95-113.

Ugarte, M. (2007). La ética empresarial como creación de valor. Gestión en el tercer milenio, 10(19). 